\title{
Cataract progression in India
}

M Srinivasan, Rahim Rahmathullah, Clifford R Blair, Aparna C Murphy, Roy W Beck, John H Wilkins, John P Whitcher, Gilbert Smolin

\begin{abstract}
Aims-The study was undertaken to test the feasibility of using the LOCS III cataract grading scale in the field and to determine the rate of cataract progression over a 1 year period of time.

Methods-For 150 subjects between the ages of 33 and 55 who attended the refraction clinic at Aravind Eye Hospital in Madurai, India, lens abnormalities were graded at the slit lamp using the LOCS III scale. One year later, 99 of the subjects were re-evaluated by the same methodology to assess the amount of lens change. Results-Interrater reliability was high. A change of 0.5 or more in lens colour, cortical, nuclear, or posterior subcapsular cataract was observed in at least one eye of $54 \%$ of the subjects.
\end{abstract}

Conclusion-The LOCS III grading scale is a feasible method for measuring lens changes in the field with the slit lamp. Cataract progression in India is rapid enough to permit intervention studies to be performed with relatively small numbers of subjects over a short period of time (that is, $\mathbf{6 0 0}$ subjects for $\mathbf{2}$ years).

(Br F Ophthalmol 1997;81:896-900)

Madurai, India

M Srinivasan

R Rahmathullah

Jaeb Center for Health Research Inc, Tampa, Florida, USA

C R Blair

A C Murphy

R W Beck

Devers Eye Clinic, Portland, Oregon, USA

J H Wilkins

Francis I Proctor

Foundation for

Research in

Ophthalmology,

University of

California, San

Francisco, and Deloris

Lange Foundation for

International Eye

Research, San

Francisco, California, USA

J P Whitcher

G Smolin

Correspondence to:

Dr Gilbert Smolin, Francis I

Proctor Foundation, UCSF

Box 0944, San Francisco,

CA 94143-0944, USA.

Accepted for publication 26 March 1977 has been inferred from incidence and prevalence studies that approximately 38 million people are blind worldwide using the World Health Organisation (WHO) definition of $20 / 400$ vision in the better seeing eye. ${ }^{1}$ Cataract represents more than $50 \%$ of all blindness. ${ }^{2}$ The incidence of cataract is approximately $20 \%$ of the prevalence figure. ${ }^{2}$ Thus, for example, the incidence of new blind cataract patients in India is about one million per year since there are 4.7 million people blind with cataracts in India. Many times those numbers are visually impaired. Minassian and Mehra's study suggests a much higher figure of 3.8 million blinded by cataract each year in India. ${ }^{3}$

Whatever the exact numbers may be, the problem is enormous. The burden of these blind people falls heaviest on the developing nations of the world where prevalence rates are significantly higher than in the USA. For example, in India the prevalence rates are more than double those in the USA and the number of people becoming blind from cataracts each year exceeds the number of surgeries performed for cataracts each year. ${ }^{4}$ Even in the USA the problem is a significant health issue. The cost of cataract surgery is estimated to be over US $\$ 3.4$ billion dollars for over 540000 surgeries annually ${ }^{5}$ and the number of doctors' office visits made each year because of cataracts is approximately 3.5 million.

There is no disputing the enormity of the problem. The financial burden and morbidity to those affected with cataracts is overwhelming. In addition, patients who are legally blind by WHO standards may not be eligible for surgery in cataract camps where, often, hand motion vision is the requirement for intervention (Professor Sundar Raj, Chief, Madras Eye Hospital, Madras, India, personal communication, 1990). The cost of performing surgery even in a camp is high and the results frequently less than ideal. Endophthalmitis rates as high as $10 \%$ have been noted (Dr Pokhrel, chief, Bir Hospital Kathmandu, Nepal, personal communication, 1988).

There is relative consensus among people studying the problem that the long term solution does not lie in the area of more surgery, although more inexpensive, rapid, efficient techniques performed on greater numbers of people is a definite goal. The area that holds the greatest promise is the one of prevention. Should a factor be found to delay cataract onset by 10 years, the number of cataract operations performed in the USA would decrease by $45 \%$ over that 10 year period ${ }^{6}$ and the number of cataract blind in the world would decrease by approximately 10 million.

To address the prevention problem one must solve a number of issues. Firstly, one must discover the risk factors. Secondly, one must be able accurately to grade the cataract progression. Thirdly, it would be best to know the progression rate, and fourthly, a study must be performed demonstrating a beneficial effect from elimination or neutralisation of one or more of the significant risk factors. Hopefully, this intervention will be cost effective and relatively easy to carry out worldwide.

There has been a great deal of research regarding the risk factors for cataract development. ${ }^{78}$ There appear to be two phenomena which interact to produce greater and earlier development of cataract in the developing world. These are (a) the increased photo-oxidation which occurs as a result of greater exposure to ultraviolet rays (because of occupation and geography) and (b) the prevalence of nutritional deficiencies in children and adults. ${ }^{9-12}$

It has also been demonstrated in vitro that continued photocatalytic generation of superoxide radicals (by ambient light) can initiate the oxidation of lens lipids with eventual formation of cataracts. Antioxidants, such as vitamins C 


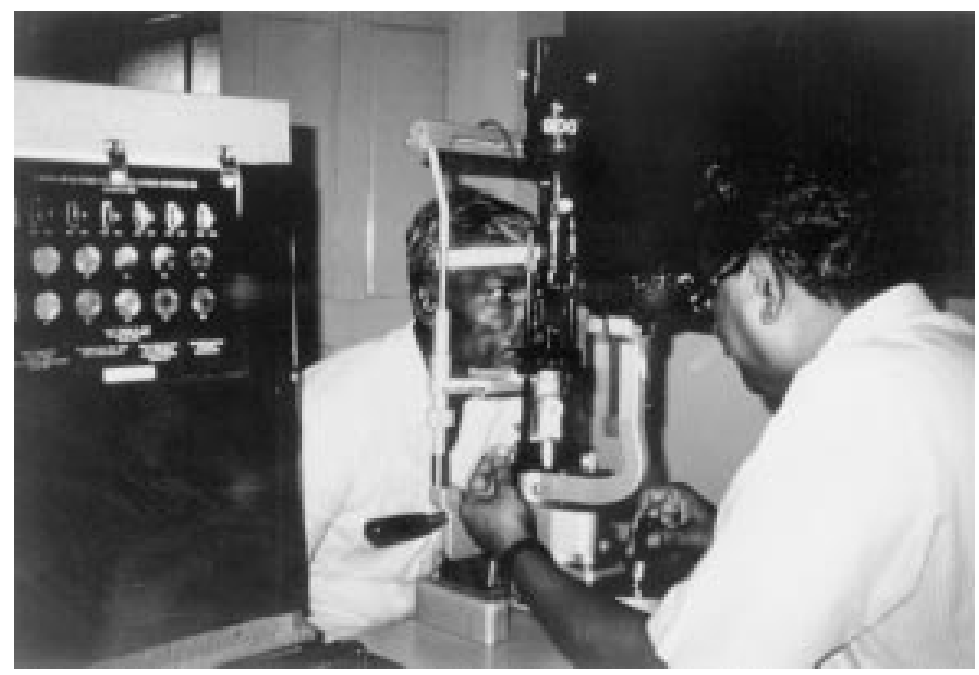

Figure 1 The arrangement at Aravind Hospital, Madurai, India, for examining and grading the subjects at the slit lamp.

and $\mathrm{E}$, superoxide dismutase, and catalase can prevent this cataract development. ${ }^{13-15}$

The second problem of accurate lens grading has been recently resolved. There are presently a number of methods available for cataract grading. ${ }^{16-18}$ We chose to employ the Lens Opacities Classification System III (LOCS III) in our study. The LOCS was designed for clinical or photographic classification of human cataract. ${ }^{1920}$ Colour slit lamp transparencies are used as standards to grade nuclear opalescence (NO), cortical (C), posterior subcapsular (PS) cataract, and lens colour (NC). Although LOCS II was used effectively to study cataract progression ${ }^{21}$ the system had some weaknesses. These included: (1) the scale for colour grading was small and the guidelines for grading colour were ambiguous; (2) the early stages of the nuclear cataract were under-represented; (3) the scaling intervals on all scales were unequal; (4) the PS cataract scale under-represents the early changes; (5) the $95 \%$ tolerance limits were large because an integer scale was used.

LOCS III was developed to correct many of these problems. The number of standards has been expanded, the intervals between grades is now based on validated objective methods and the sensitivity of the system has been improved by the use of the decimal method for grading. ${ }^{22}$

The purpose of this study was to test the feasibility of LOCS III in the field and to determine the rate of cataract progression over a 1 year period.

\section{Materials and methods}

The study was performed at Aravind Eye Hospital in Madurai, India. The 150 subjects (109 men and 41 women) were selected from the refraction clinic. Subjects who fitted the entrance criteria were selected the week before the study was to begin. The first 170 who said they would be able to return were entered. Of these, 150 returned. The subjects were between the ages of 33 and 57 (mean age 45) and had no history of systemic disorders or drug exposure that may predispose to cataracts (that is, diabetes, corticosteroid therapy, irradiation). Excluded were subjects with a best corrected visual acuity of less than 20/40, patients who had previous intraocular surgery, subjects with secondary cataracts, congenital cataracts, and mature cataracts visible to the naked eye.

All patients were examined at baseline (in 1994); 11 were re-evaluated the day of their examination to assess intraobserver reliability. Ninety nine subjects returned for a follow up examination after 12 months.

In the 1994 grading, one subject had only a right eye suitable for grading and one only a left. In the 1995 grading, two subjects had only a right eye and two only a left suitable for grading. Cataracts had been previously removed in these eyes.

The examiners were masked as to the gradings of the other examiners and to each subject's previous grading (in the 1 year follow up visit). The same four observers (ophthalmologists) re-examined the subjects at the 12 month interval. Both eyes were maximally dilated using three doses of $0.8 \%$ tropicamide and $5.0 \%$ Neosynephrine eyedrops (phenylephrine hydrochloride; Milnet Co, India).

Ophthalmology residents and social workers recorded the relevant history, sex, and age of the subjects; checked the visual acuity; quickly refracted the subjects; and then instilled the dilating drops.

There were four slit lamps set up in the examining room. The four observers rotated from one slit lamp to the next and, thus, each subject was examined at the same slit lamp. The slit-lamp number was recorded on the patient's information sheet and the patient was examined at the same slit lamp the following year (Fig 1). The LOCS III grading transparencies were placed at the subject's shoulder between two slit lamps. These were mounted on $x$ ray light boxes. The area not covered by the transparency was blacked out to eliminate unnecessary light. The drapes were pulled and the lighting adjusted and recorded. The lighting situation was recorded and recreated the following year.

Every day before beginning the grading of the subjects, three subjects, not in this study, were examined, graded, and discussed by all of the observers to enhance adherence of graders to the LOCS III system.

Interobserver reliability was assessed for each of the four LOCS III measures for both the 1994 and 1995 gradings by computing intraclass correlation coefficients ${ }^{23}$ as well as Pearson correlation coefficients for all combinations of pairs of examiners. Spearman correlation coefficients, not reported herein, were also computed and were very similar to the others. For all three methods, right and left eye results were virtually identical; only right eye correlation coefficients are reported here.

The reliability of the scores of the four examiners were also assessed by computing standard errors of measurements for the 1994 and 1995 gradings as well as for the change from 1994 to 1995. 
Table 1 Average LOCS III values for the four examiners from 1994 to 1995

\begin{tabular}{|c|c|c|c|c|}
\hline & \multicolumn{4}{|c|}{ Type of lens opacity } \\
\hline & Cortical & Nuclear opalescence & Posterior subcapsular & Nuclear colour \\
\hline \multicolumn{5}{|l|}{ 1994: } \\
\hline No & 149 & 149 & 149 & 149 \\
\hline Median & 0.6 & 2.3 & 0.2 & 2.2 \\
\hline 25th, 75 th $\%$ & $0.3,1.1$ & $2.1,2.9$ & $0.2,0.3$ & $1.8,2.8$ \\
\hline Range & $0.2,3.5$ & $1.7,5.6$ & $0.1,5.7$ & $0.9,6.3$ \\
\hline \multicolumn{5}{|l|}{ Left eyes } \\
\hline No & 149 & 149 & 149 & 149 \\
\hline Median & 0.6 & 2.4 & 0.2 & 2.2 \\
\hline 25th, 75 th $\%$ & $0.3,1.2$ & $2.1,2.9$ & $0.2,0.3$ & $1.8,2.8$ \\
\hline Range & $0.2,3.4$ & $1.7,5.8$ & $0.1,5.7$ & $0.8,6.4$ \\
\hline \multicolumn{5}{|l|}{ 1995: } \\
\hline \multicolumn{5}{|l|}{ Right eyes } \\
\hline No & 97 & 97 & 97 & 97 \\
\hline Median & 0.6 & 2.5 & 0.1 & 2.4 \\
\hline 25 th, 75 th $\%$ & $0.3,1.4$ & $2.3,2.9$ & $0.1,0.2$ & $2.1,2.9$ \\
\hline Range & $0.2,4.3$ & $1.9,5.7$ & $0.1,5.4$ & $1.4,6.1$ \\
\hline \multicolumn{5}{|l|}{ Left eyes } \\
\hline No & 97 & 97 & 97 & 97 \\
\hline Median & 0.6 & 2.6 & 0.1 & 2.4 \\
\hline 25 th, 75 th $\%$ & $0.4,1.5$ & $2.4,2.9$ & $0.1,0.2$ & $2.1,3.0$ \\
\hline Range & $0.2,3.2$ & $2.0,5.9$ & $0.1,4.3$ & $1.6,6.3$ \\
\hline
\end{tabular}

For purpose of analysis, a 0.5 unit change from 1994 to 1995 was considered to be the minimum clinically relevant amount of worsening.

\section{Results}

LOCS III GRADINGS 1994 AND 1995

Table 1 presents the distribution of cataract gradings for each of the four measures (NC, PS, C, and NO) for 1994 and 1995. A majority of subjects had some abnormality in NC and NO but only a minority had significant abnormality in the cortical and posterior subcapsular portions of the lens.

Table 2 Average change on LOCS III scale for four examiners from 1994 to 1995

\begin{tabular}{|c|c|c|c|c|}
\hline & \multicolumn{4}{|c|}{ Type of lens opacity } \\
\hline & Cortical & Nuclear opalescence & Posterior subcapsular & Nuclear colour \\
\hline \multicolumn{5}{|l|}{ Right eye: } \\
\hline \multicolumn{5}{|l|}{ Total } \\
\hline No & 97 & 97 & 97 & 97 \\
\hline Median & 0.0 & 0.2 & 0.0 & 0.3 \\
\hline 25 th, 75 th $\%$ & $-0.1,0.2$ & $0.1,0.4$ & $-0.1,0.0$ & $-0.0,0.7$ \\
\hline \multicolumn{4}{|c|}{ Abnormal in $1994^{*}$} & $-0.9,1.9$ \\
\hline No & 25 & 83 & 12 & 62 \\
\hline Median & -0.1 & 0.2 & 0.4 & 0.2 \\
\hline 25 th, 75 th $\%$ & $-0.3,0.3$ & $0.0,0.4$ & $0.0,0.7$ & $-0.2,0.5$ \\
\hline Range & $-0.8,1.2$ & $-0.5,1.4$ & $-0.4,1.6$ & -0.9 .1 .9 \\
\hline \multicolumn{5}{|c|}{ Normal in $1994^{\star}$} \\
\hline No & 72 & 14 & 85 & 35 \\
\hline Median & 0.0 & 0.5 & 0.0 & 0.5 \\
\hline 25 th, 75 th $\%$ & $-0.1,0.2$ & $0.3,0.6$ & $-0.1,0.0$ & $0.3,0.7$ \\
\hline Range & $-0.4,3.7$ & $0.2,0.8$ & $-0.4,1.9$ & $-0.1,1.3$ \\
\hline \multicolumn{5}{|l|}{ Left eye: } \\
\hline \multicolumn{5}{|l|}{ Total } \\
\hline No & 97 & 97 & 97 & 97 \\
\hline Median & 0.1 & 0.2 & 0.0 & 0.3 \\
\hline 25 th, 75 th $\%$ & $-0.1,0.3$ & $0.1,0.3$ & $-0.1,0.0$ & $0.1,0.6$ \\
\hline \multirow{2}{*}{\multicolumn{5}{|c|}{ Abnormal in 1994* }} \\
\hline & & & & \\
\hline No & 28 & 88 & 15 & 65 \\
\hline Median & 0.1 & 0.2 & 0.1 & 0.2 \\
\hline 25 th, 75 th $\%$ & $-0.2,0.5$ & $0.1,0.3$ & $-0.2,0.7$ & $-0.1,0.5$ \\
\hline Range & $-0.7,1.1$ & $-0.5,1.0$ & $-0.6,1.7$ & $-0.8,1.6$ \\
\hline \multicolumn{5}{|c|}{ Normal in $1994^{\star}$} \\
\hline No & 69 & 9 & 82 & 32 \\
\hline Median & 0.1 & 0.6 & 0.0 & 0.5 \\
\hline 25 th, 75 th $\%$ & $-0.1,0.3$ & $0.4,0.6$ & $-0.1,0.0$ & $0.3,0.7$ \\
\hline Range & $-0.4,1.6$ & $0.2,0.9$ & $-0.3,0.4$ & $0.0,1.3$ \\
\hline
\end{tabular}

*Abnormality at baseline (1994) on the LOCS-III scale defined for cortical as $\geqslant 1$, for nuclear opacity as $\geqslant 2$, for posterior subcapsular as $\geqslant 1$, and for nuclear colour as $\geqslant 2$.
CHANGES IN THE LENS FROM 1994 TO 1995

Table 2 provides the distribution of changes for each of the four LOCS III measures from 1994 to 1995 . There was no clear pattern of differences in progression rate when the eyes were divided into those that had abnormality at baseline (1994) and those that did not.

Fifty four per cent of the 99 subjects worsened 0.5 or more on at least one measure in one or both eyes $(22 \%$ in one eye and $32 \%$ in both eyes) (Table 3). At least 0.5 change occurred in one or both eyes in $18 \%$ for $\mathrm{C}$, $16 \%$ for NO, $42 \%$ for NC, and $8 \%$ for PS.

\section{INTEROBSERVER RELIABILITY}

Tables 4 and 5 for 1994 and Tables 6 and 7 for 1995 demonstrate that the correlation between pairs of examiners was high for all four measures of the right eyes. The magnitude of the correlation coefficients generally was slightly lower when only eyes were included with meaningful abnormality on a measure (Tables 5 and 7 ). The results for the left eyes were similar (data not shown).

Table 8 provides the standard error of measurement for the four observers for the 1994 and 1995 gradings as well as for the assessment of change from 1994 to 1995. As expected, the standard errors were slightly higher for the assessments of change than for the individual 1994 and 1995 assessments. The results for right and left eyes were quite similar.

\section{Discussion}

The 150 subjects who were entered in this study were selected in a non-systematic manner from the refraction clinic by the Aravind Eye Hospital personnel. The criteria for exclusion are listed in the Methods section. The subjects were between the ages of 35 and 55 and had a correctible visual acuity of $20 / 40$ or better. The majority of subjects seen in the clinic were males and this is reflected in our sample (approximately two thirds were male).

The 99 subjects re-examined after 12 months were similar in demographic characteristics to the original 150 subjects. The reason for the non-appearance seemed random. The personnel at Aravind Eye Hospital have performed numerous epidemiological studies and their experience suggests that subjects do not appear for logistic reasons (distance, work commitments, availability of transport, etc). Incentives (payment for cost of transport, free medical care, etc) could have increased the return rate. The dropout rate in village based studies is about $10 \%$ per year. The dropout rate for a non-incentive hospital based study such as ours was not known before this study.

A change of 0.3 or more in one of the four cataract measurements was observed in $77 \%$ of the eyes. We selected the more conservative 0.5 or more change to represent the minimum amount of change that was clinically relevant and still noted a change in at least one eye of $54 \%$ of the patients in the 12 month interval. Eighty two per cent of the eyes had no detect- 
Table 3 Changes of $\geqslant 0.5$ on LOCS III scale from 1994 to 1995

\begin{tabular}{|c|c|c|c|c|c|}
\hline & \multicolumn{5}{|c|}{ Type of lens opacity } \\
\hline & Cortical & Nuclear opalescence & Posterior subcapsular & Nuclear colour & Any of 4 \\
\hline $\begin{array}{l}\text { All patients: } \\
\text { Change developed }\end{array}$ & $\mathrm{n}=99$ & $\mathrm{n}=99$ & $\mathrm{n}=99$ & $\mathrm{n}=99$ & $\mathrm{n}=99$ \\
\hline Neither eye & $82 \%$ & $84 \%$ & $91 \%$ & $58 \%$ & $46 \%$ \\
\hline One eye & $8 \%$ & $8 \%$ & $5 \%$ & $18 \%$ & $22 \%$ \\
\hline Both eyes & $10 \%$ & $8 \%$ & $3 \%$ & $24 \%$ & $32 \%$ \\
\hline $\begin{array}{l}\text { Patients with abnormality at baseline }{ }^{\star} \text { : } \\
\text { Change developed }\end{array}$ & $\mathrm{n}=32$ & $\mathrm{n}=91$ & $\mathrm{n}=16$ & $\mathrm{n}=68$ & $\mathrm{n}=92$ \\
\hline Neither eye & $75 \%$ & $89 \%$ & $56 \%$ & $68 \%$ & $48 \%$ \\
\hline One eye & $16 \%$ & $7 \%$ & $25 \%$ & $15 \%$ & $24 \%$ \\
\hline Both eyes & $9 \%$ & $4 \%$ & $19 \%$ & $18 \%$ & $28 \%$ \\
\hline $\begin{array}{l}\text { Patients without abnormality at } \\
\text { baselinet: } \\
\text { Change developed }\end{array}$ & $\mathrm{n}=67$ & $\mathrm{n}=8$ & $\mathrm{n}=83$ & $\mathrm{n}=31$ & $\mathrm{n}=7$ \\
\hline Neither eye & $85 \%$ & $25 \%$ & $99 \%$ & $36 \%$ & $14 \%$ \\
\hline One eye & $5 \%$ & $25 \%$ & $1 \%$ & $26 \%$ & $0 \%$ \\
\hline Both eyes & $10 \%$ & $50 \%$ & $0 \%$ & $39 \%$ & $86 \%$ \\
\hline
\end{tabular}

^Abnormality at baseline (1994) defined as the presence in at least one eye of a LOCS-III score for cortical $\geqslant 1$, for nuclear opacity $\geqslant 2$, for posterior subcapsular $\geqslant 1$, and for nuclear colour $\geqslant 2$.

†Based on the average value for each patient for the four examiners.

able PS. Of those patients with a baseline score of 1 or greater in the PS in one or both eyes, $44 \%$ changed 0.5 or more in at least one eye.

The progression rate of cataract development in the developing world has not been previously determined. Data such as ours are essential in planning interventional studies.

The probability appears high that the observed lens changes from 1994 to 1995 were real. However, the possibility exists that the change could have been due to a drift in measurement (systematically the four examiners tended to grade higher in 1995 than in 1994). As evidence against this, the consist-

Table 4 Interobserver correlations for right eyes for 1994*

\begin{tabular}{lllll}
\hline Examiners & $\begin{array}{l}\text { Cortical } \\
(n=149)\end{array}$ & $\begin{array}{l}\text { Nuclear } \\
\text { opalescence } \\
(n=149)\end{array}$ & $\begin{array}{l}\text { Posterior } \\
\text { subcapsular } \\
(n=149)\end{array}$ & $\begin{array}{l}\text { Nuclear } \\
\text { colour } \\
(n=149)\end{array}$ \\
\hline $\mathrm{A} v \mathrm{~B}$ & 0.81 & 0.83 & 0.94 & 0.84 \\
& $(0.82)$ & $(0.83)$ & $(0.95)$ & $(0.86)$ \\
$\mathrm{A} v \mathrm{C}$ & 0.81 & 0.83 & 0.93 & 0.84 \\
& $(0.82)$ & $(0.84)$ & $(0.94)$ & $(0.86)$ \\
$\mathrm{A} v \mathrm{D}$ & 0.84 & 0.80 & 0.93 & 0.68 \\
& $(0.83)$ & $(0.82)$ & $(0.94)$ & $(0.71)$ \\
$\mathrm{B} v \mathrm{C}$ & 0.87 & 0.79 & 0.95 & 0.81 \\
& $(0.87)$ & $(0.79)$ & $(0.95)$ & $(0.81)$ \\
$\mathrm{B} v \mathrm{D}$ & 0.82 & 0.75 & 0.95 & 0.60 \\
& $(0.84)$ & $(0.78)$ & $(0.95)$ & $(0.67)$ \\
$\mathrm{C} v \mathrm{D}$ & 0.77 & 0.76 & 0.93 & 0.63 \\
& $(0.78)$ & $(0.77)$ & $(0.83)$ & $(0.69)$ \\
All 4 raters & 0.83 & 0.79 & 0.95 & 0.75 \\
\hline
\end{tabular}

* The top row of each paired comparison is the intraclass correlation coefficient and the second row in parentheses is the Pearson correlation coefficient.

Table 5 Only right eyes with abnormality present*

\begin{tabular}{lllll}
\hline Examiners & $\begin{array}{l}\text { Cortical } \\
(n=42)\end{array}$ & $\begin{array}{l}\text { Nuclear } \\
\text { opalescence } \\
(n=124)\end{array}$ & $\begin{array}{l}\text { Posterior } \\
\text { subcapsular } \\
(n=18)\end{array}$ & $\begin{array}{l}\text { Nuclear } \\
\text { colour } \\
(n=96)\end{array}$ \\
\hline A v B & 0.65 & 0.82 & 0.89 & 0.79 \\
& $(0.69)$ & $(0.81)$ & $(0.90)$ & $(0.82)$ \\
$\mathrm{A} v \mathrm{C}$ & 0.66 & 0.83 & 0.81 & 0.78 \\
& $(0.66)$ & $(0.83)$ & $(0.80)$ & $(0.80)$ \\
$\mathrm{A} v \mathrm{D}$ & 0.71 & 0.80 & 0.86 & 0.60 \\
& $(0.72)$ & $(0.81)$ & $(0.86)$ & $(0.64)$ \\
$\mathrm{B} v \mathrm{C}$ & 0.78 & 0.79 & 0.91 & 0.74 \\
& $(0.81)$ & $(0.79)$ & $(0.91)$ & $(0.75)$ \\
$\mathrm{B} v \mathrm{D}$ & 0.61 & 0.76 & 0.86 & 0.48 \\
& $(0.67)$ & $(0.77)$ & $(0.87)$ & $(0.58)$ \\
$\mathrm{C} v \mathrm{D}$ & 0.55 & 0.74 & 0.82 & 0.52 \\
& $(0.56)$ & $(0.75)$ & $(0.82)$ & $(0.61)$ \\
All 4 raters & 0.65 & 0.79 & 0.87 & 0.65 \\
\hline
\end{tabular}

$\star$ Defined for cortical as $\geqslant 1$, for nuclear opalescence as $\geqslant 2$, for posterior subcapsular as $\geqslant 1$, and for nuclear colour as $\geqslant 2$. ency of the findings between examiners and the fact that the examiners were not aware of the 1994 gradings at the time of the 1995 gradings support the change being real. In addition, because of the length of the time between the two gradings (12 months), it is unlikely that the change reflected a learning effect on the part of the examiners.

The interobserver reliability of the measurements was high. The morning checks on adherence to the LOCS III system were helpful, as well as limiting the number of sub-

Table 6 Interobserver correlations for all right eyes for $1995^{\star}$

\begin{tabular}{lllll}
\hline Examiners & $\begin{array}{l}\text { Cortical } \\
(n=97)\end{array}$ & $\begin{array}{l}\text { Nuclear } \\
\text { opalescence } \\
(n=97)\end{array}$ & $\begin{array}{l}\text { Posterior } \\
\text { subcapsular } \\
(n=97)\end{array}$ & $\begin{array}{l}\text { Nuclear } \\
\text { colour } \\
(n=97)\end{array}$ \\
\hline A v B & 0.87 & 0.80 & 0.88 & 0.88 \\
& $(0.87)$ & $(0.80)$ & $(0.88)$ & $(0.89)$ \\
$\mathrm{A} v \mathrm{C}$ & 0.86 & 0.80 & 0.86 & 0.88 \\
& $(0.87)$ & $(0.80)$ & $(0.43)$ & $(0.87)$ \\
$\mathrm{A} v \mathrm{D}$ & 0.82 & 0.76 & 0.88 & 0.79 \\
& $(0.84)$ & $(0.74)$ & $(0.89)$ & $(0.82)$ \\
$\mathrm{B} v \mathrm{C}$ & 0.90 & 0.73 & 0.90 & 0.86 \\
& $(0.90)$ & $(0.72)$ & $(0.92)$ & $(0.86)$ \\
$\mathrm{B} v \mathrm{D}$ & 0.81 & 0.77 & 0.95 & 0.79 \\
& $(0.65)$ & $(0.78)$ & $(0.96)$ & $(0.76)$ \\
$\mathrm{C} v \mathrm{D}$ & 0.84 & 0.76 & 0.96 & 0.77 \\
& $(0.84)$ & $(0.76)$ & $(0.96)$ & $(0.81)$ \\
All 4 raters & 0.85 & 0.77 & 0.91 & 0.82 \\
\hline
\end{tabular}

* The top row of each paired comparison is the intraclass correlation coefficient and the second row in parenthesis is the Pearson correlation coefficient.

Table 7 Only right eyes with abnormality present *

\begin{tabular}{lllll}
\hline Examiners & $\begin{array}{l}\text { Cortical } \\
(n=32)\end{array}$ & $\begin{array}{l}\text { Nuclear } \\
\text { opalescence } \\
(n=95)\end{array}$ & $\begin{array}{l}\text { Posterior } \\
\text { subcapsular } \\
(n=14)\end{array}$ & $\begin{array}{l}\text { Nuclear } \\
\text { colour } \\
(n=79)\end{array}$ \\
\hline A v B & 0.69 & 0.84 & 0.52 & 0.89 \\
& $(0.69)$ & $(0.85)$ & $(0.57)$ & $(0.90)$ \\
A v C & 0.70 & 0.81 & 0.37 & 0.86 \\
& $(0.70)$ & $(0.81)$ & $(0.43)$ & $(0.86)$ \\
A v D & 0.61 & 0.77 & 0.46 & 0.76 \\
& $(0.63)$ & $(0.77)$ & $(0.51)$ & $(0.80)$ \\
B v C & 0.77 & 0.72 & 0.74 & 0.85 \\
& $(0.78)$ & $(0.72)$ & $(0.75)$ & $(0.85)$ \\
B v D & 0.59 & 0.77 & 0.89 & 0.67 \\
& $(0.65)$ & $(0.78)$ & $(0.90)$ & $(0.76)$ \\
C v D & 0.60 & 0.76 & 0.86 & 0.73 \\
& $(0.62)$ & $(0.76)$ & $(0.86)$ & $(0.78)$ \\
All 4 raters & 0.65 & 0.78 & 0.65 & 0.80 \\
\hline
\end{tabular}

$\star$ Defined for cortical as $\geqslant 1$, for nuclear opalescence as $\geqslant 2$, for posterior subcapsular as $\geqslant 1$, and for nuclear colour as $\geqslant 2$. 
Table 8 Standard error of measurement for four examiners

\begin{tabular}{lllll}
\hline \multicolumn{5}{l}{ Type of lens opacity } \\
& Cortical & Nuclear opalescence & Posterior subcapsular & Nuclear colour \\
\cline { 3 - 5 } & & & & \\
1994: & 149 & 149 & 149 & 149 \\
No & 0.36 & 0.34 & 0.21 & 0.52 \\
Right eye & 0.33 & 0.34 & 0.19 & 0.50 \\
Left eye & & & & \\
1995: & 97 & 97 & 97 & 07 \\
No & 0.33 & 0.38 & 0.29 & 0.42 \\
Right eye & 0.34 & 0.38 & 0.30 & 97 \\
Left eye & & & 97 & 0.56 \\
Change 1994 to 1995: & 97 & 97 & 0.37 & 0.55 \\
No & 0.45 & 0.47 & 0.34 & \\
Right eye & 0.45 & 0.44 & & \\
Left eye & & & & \\
\hline
\end{tabular}

jects examined per day. The examiners were not exhausted for the later gradings.

This study validates the reliability of LOCS III and the slit-lamp method of examination in the field. Previous investigators have reported the reliability of the slit-lamp method versus the photographic method of grading the LOCS III. ${ }^{22}$

As already noted, the results of this study can be used to estimate the sample size requirements for a randomised treatment trial designed to determine whether a particular therapy can effectively reduce the progression of lens changes. A value equal to twice the standard error of measurement is the amount of change that should be exceeded to have a high level of confidence that the change is real. For all four measures this would be achieved by defining progression as a 1.0 or more unit change on the LOCS III scale. Assuming that the rate of change over 2 years would be twice that of 1 year, for a 2 year treatment trial, the expected rate of change in the control group can be estimated by the frequency of changes of 0.5 or more that were observed over a 1 year follow up period in the current study. For an outcome definition of change of 1.0 on any of the four measures in either eye over a 2 year period, the control group rate would be expected to be $54 \%$. Assuming a type 1 error rate of $5 \%$ and an expected dropout rate of $20 \%, 600$ subjects would be needed to have $90 \%$ power to detect a $30 \%$ treatment effect.
This information is presently being applied to our interventional study.

1 World Health Organisation. Available data on blindness (Update 1987). WHO PBL/87.14. Geneva: World Health Organisation, 1987.

2 Foster A. Worldwide blindness, increasing but avoidable! Sem Ophthalmol 1993;8:166-70.

3 Minassian DC, Mehra V. 3.8 million blinded by cataract each year; projections from the first epidemiological study each year; projections from the first epidemiological study
of incidence of cataract blindness in India. Brf Ophthalmol of incidence of

4 Vishnubhatla S, Amble PK. Incidence estimates of cataract in India. Ann Natl Acad Sci (India) 1994;30:9-16.

5 Cataract Management Guideline Panel. Cataract in adults. Clinical Practice Guideline Number 4. Rockville, MD: US Department of Public Health and Human Services AHCPR Pub No 93-0542, February 1993.

6 Kupfer C. Bowman lecture. The conquest of cataract: a global challenge. Trans Ophthalmol Soc UK 1984;104:1-10.

7 Minassian DC, Mehra V, Verrey JD. Dehydrational crisis: a major risk factor in blinding cataract. $\mathrm{Br} \mathcal{F}$ Ophthalmol 1989;73:100-5.

8 Collman GW, Shore DL, Shy CM. Sunlight and other risk factors for cataracts: an epidemiological study. Am $\mathcal{F}$ Public Health 1988;78:1459-62.

9 Cummings SR, Block G, McKenry K, Baron RB. Evaluation of two food frequency methods for measuring dietary calcium intake. Am f Epidemiol 1987;126:796-802.

10 Bunce GE, Kinoshita J, Horwitz JH. Nutritional factors in cataract. Ann Rev Nutr 1990;10:233-54.

11 Byers T, Marshall J, Fiedler R. Assessing nutrient intake with an abbreviated dietary interview. $\mathrm{Am} \mathcal{F}$ Epidemiol 1985;122:41-50.

12 Chatterjee A, Milton RC, Thyle S. Prevalence and aetiology of cataract in Punjab. Br f Ophthalmol 1982;66:35-42.

13 Varma SD, Srivastava VK, Richards RD. Photoperoxidation in lens and cataract formation: Preventive role of superoxide dismutase catalase and vitamin C. Ophthalmol Res 1982;14:167-74.

14 Varma SD, Beachy NA, Richards RD. Photoperoxidation of lens lipids. Prevention by vitamin E. Photochem Photobiol 1982;6:623-7.

15 Varma SD, Kumar S, Richards RD. Light-induced damage to ocular lens cation pump: Prevention by vitamin Ca. Proc Natl Acad Sci USA 1979;76:3504-7.

16 Chylack LT Jr, Wolfe JK, Singer DM, Leske MC, Bullimore MA, Bailey IL, et al. The lens opacities classification system III. Arch Ophthalmol 1993;111:831-6.

7 Sparrow JM. Methods of clinical cataract grading: two systems compared. Arch Ophthalmol 1990;108:1209-11.

18 Taylor HR, Lee JA, Wang F, Munoz B. A comparison of two photographic systems for grading cataract. Invest Ophthalmol Vis Sci 1991;32:529-32.

19 Chylack LT Jr, Leske MC, McCarthy D, Khu P, Kashiwagi T, Sperduto R. Opacities classification system II. Arch Ophthalmol 1989;107:991-7.

20 Maraini G, Pasquini P, Tomba MC, Bonacini M, Stazi MA, Rosmini F, et al. The Italian-American Cataract Study Group. An independent evaluation of the LOCS II. Ophthalmology 1989;96:611-5.

21 Magno BV, Datiles MB III, Lasa SM. Senile cataract progression studies using the lens opacities classification system II. Invest Ophthalmol Vis Sci 1993;34:2138-41.

22 Karbassi M, Khu PM, Singer DM, Chylack LT Jr. Evaluation of lens opacities classification system III applied at a slitlamp. Optom Vis Sci 1993;70:923-8.

23 Crocker L, Algina J. Introduction to classical and modern test theory. New York: Harcourt, Brace, Jovanovich, 1986:169. 